\title{
Economic assessment of postoperative pain control strategies for treatment of adult patients with cancer
}

\author{
Rafael Freitas dos Santos ${ }^{1}$, Fernando Bliacheriene ${ }^{2}$, Flavia Mori Sartio ${ }^{3 *}$ \\ ${ }^{1}$ Pharmacy degree from Universidade de São Paulo (USP), São Paulo, SP, Brazil \\ ${ }^{2} \mathrm{MD}, \mathrm{PhD}$ in Medicine from Faculdade de Medicina da USP (FMUSP), São Paulo, SP Brazil \\ ${ }^{3}$ Economist and Nutritionist, PhD in Applied Human Nutrition from USP, São Paulo, SP, Brazil
}

Study conducted at Faculdade de Ciências Farmacêuticas e Escola de Artes, Ciências e Humanidades da Universidade de São Paulo (USP), São Paulo, SP, Brazil

Article received: 3/6/2017 Accepted for publication: 4/3/2017

*Correspondence: Address: Av. Arlindo Béttio, 1.000 São Paulo, SP - Brazil Postal code: $03828-000$ flamori@usp.br

\section{SUMMARY}

Objective: The authors performed an economic assessment of opioids currently being used for control of postoperative pain relating to the surgical treatment of cancer (fentanyl and sufentanil) within the Brazilian Unified Health System (SUS, in the Portuguese acronym).

Method: The assessment was based on the perspective of the government, in order to collaborate with the promotion of effectiveness in public policies of health, and to optimize the allocation of public resources into health. A cost-effectiveness analysis was performed using data collected from the Brazilian Unified Health System and information from literature review, in order to build a decision tree on the alternatives for control of postoperative pain related to cancer treatment among adult patients. The outcomes considered were: effectiveness of postoperative analgesia and occurrence of nausea and vomit in the 48 hour period after surgery, and additional 24-hour cycles in patient follow-up. A univariate sensitivity analysis was conducted in order to verify robustness of the model estimated.

Results: Literature review showed a limited number of studies directly comparing fentanyl and sufentanil for control of postoperative pain. The adoption of sufentanil (cost $=\mathrm{U} \$ 25.72 /$ outcome $=1.6 \mathrm{VAS}$ points) was dominant in relation to the use of fentanyl (cost $=\mathrm{U} \$ 32.58 /$ outcome $=2.6$ VAS points). The estimated model showed robustness in relation to changes in the parameters analyzed.

Conclusion: Sufentanil presented higher cost-effectiveness ratio in relation to fentanyl for control of postoperative pain in surgeries related to cancer treatment among adult patients in the Brazilian Unified Health System.

Keywords: health evaluation, analgesia, pain measurement.

\section{INTRODUCTION}

The choice of postoperative pain control strategy is a crucial factor to decrease morbidity and increase patients' quality of life. ${ }^{1}$ Opioid analgesics are broadly used for management of pain after surgical treatment of cancer, either as single therapy or associated with other drugs to leverage analgesic effect. ${ }^{2}$

Morphine is one of the most studied and commonly used opioids. However, recent evidences show that use of fentanyl and sufentanil present benefits in comparison to the use of morphine, regarding its effectiveness in maintenance of anesthesia and control of post-operative pain, as well as higher liposolubility, resulting in fewer episodes of adverse side effects in comparison to morphine. ${ }^{3}$
The health sector has limited resources to be used for multiple purposes, and within the context of public sector management in the Brazilian health system, the Brazilian Unified Health System (SUS, in the Portuguese acronym) is significantly sensitive to the costs of activities undertaken. Thus, there is need for health economics studies in order to establish cost-effective programs that may benefit a higher number of patients with equal amount of resources. ${ }^{4}$

Therefore, the aim of the paper was to perform an economic assessment of opioids currently being used for control of postoperative pain relating to surgical treatment of cancer (fentanyl and sufentanil) within the Brazilian Unified Health System, in order to collaborate 
to the promotion of effectiveness in public health policies, and to enhance the allocation of public resources in health.

\section{Method}

Our paper presents a retrospective transversal study on the costs and outcomes of strategies for postoperative pain control strategies for treatment of adult patients with cancer. The study was based on three components: literature review, economic assessment and sensitivity analysis.

\section{Literature review}

A literature search was performed on Medline/PubMed and Lilacs databases to identify clinical data available regarding effectiveness and safety of the opioids fentanyl and sufentanil for control of postoperative pain relating to cancer treatment.

The literature review was based on a structured question defining target population, intervention, comparator and outcome (PICO strategy) to perform the economic assessment using the best evidences available according to the methodological guidelines of the National Committee on Technology Incorporation for the Brazilian Unified Health System (Conitec). ${ }^{5}$

PICO represents an acronym for Patient, Intervention, Comparator and Outcome, which are four primary elements in evidence-based medicine for search of relevant information within a certain health context. The appropriate structure of the research question enables the definition of parameters necessary for estimating the model, maximizing data recovery, allowing for research scope definition and avoiding unnecessary search. ${ }^{6}$

The literature search was based on the following question: Is the adoption of sufentanil effective and safe in comparison to the use of fentanyl on postoperative analgesia relating to surgical treatment of cancer among adult patients? The question was structured based on the following parameters applied on PICO strategy:

- Patients: Adult individuals subject to surgical treatment of cancer.

- Intervention: Sufentanil.

- Comparator: Fentanyl.

- Outcomes: Effectiveness of postoperative analgesia (using Visual Analogue Scale points of pain, VAS) and safety in postoperative control of pain (incidence of adverse side effects).

The literature search was performed on Medline/ PubMed and Lilacs databases using the following key- words: "oncologic surgery," "cancer surgery," "neoplasm surgery," "cancer," "oncologic," "sufentanil," "fentanyl" and "analgesia" in three to four different quests:

- Medline/PubMed:

1. $((((((($ ("oncologic surgery”) $)$ OR "oncologic surgeries") OR "cancer surgeries”) OR "cancer surgery”) OR "neoplasm* surgery") OR "neoplasm* surgeries")) AND sufentanil) AND analgesia

2. $(((((($ ("oncologic surgery”) $O R$ "oncologic surgeries") OR "cancer surgeries”) OR "cancer surgery") OR "neoplasm* surgery") OR "neoplasm* surgeries")) AND sufentanil

3. $(((((()($ “oncologic surgery”) OR “oncologic surgeries”) OR “cancer surgeries”) OR "cancer surgery”) OR "neoplasm* surgery") OR "neoplasm* surgeries")) AND fentanyl)) AND analgesia

- Lilacs:

1. sufentanil [Palavras] and cancer [Palavras]

2. sufentanil [Palavras] and oncologica [Palavras]

3. fentanil [Palavras] and oncologica [Palavras]

4. fentanil [Palavras] and cancer [Palavras]

The records identified were analyzed, considering the following criteria for inclusion and exclusion:

\section{- Inclusion criteria:}

- Studies based on adult patients sample.

- Assessment of postoperative analgesia effectiveness using VAS.

- Main therapy based on fentanyl or sufentanil for postoperative analgesia.

- Fentanyl or sufentanil administered through intravenous or neuraxial application.

- Full-text version of the study available for analysis.

- Exclusion criteria:

- Case studies.

- Studies without side effects of interest (nausea and vomit).

- Fentanyl or sufentanil administered through mixed alternative ways (mixed intravenous with nasal or transdermal).

Effectiveness and safety data of fentanyl and sufentanil used for control of postoperative pain were extracted from each study analyzed. Information on use of resources was also collected in the literature, if available.

Parameters of effectiveness and safety data collected in the scientific literature review, an economic assessment model of costs and outcomes was estimated on the po- 
tential adoption of fentanyl and sufentanil within the Brazilian Unified Health System.

\section{Economic assessment}

The economic assessment was performed using the perspective of the Brazilian Unified Health System, including only direct medical costs covered by the government. A decision tree on the alternatives for control of postoperative pain related to cancer treatment among adult patients was built using effectiveness data from information gathered during literature review.

The decision tree considered two types of outcomes: effectiveness of postoperative analgesia (using VAS points of pain) and safety in postoperative control of pain (incidence of adverse side effects). ${ }^{7-10}$ The main adverse side effects identified in the literature review that were associated with use of opioid anesthetics for control of postoperative pain $^{7-9}$ were occurrence of nausea and vomit.

Data on incidence of adverse side effects were obtained from direct comparison between fentanyl and sufentanil performed in one of the studies identified in the literature review, ${ }^{8}$ considering nausea and vomit in the 48 hour period after surgery, and additional cycles of 24 hour in patient follow-up, in order to reproduce the practice of pain intensity measurement identified in the studies analyzed. ${ }^{7,8}$

The economic assessment was performed using the perspective of the Brazilian Unified Health System, i.e., estimation considered only direct medical costs associated with control of postoperative pain relating to surgical treatment of cancer among adult patients.

Direct medical cost estimation was based on microcosting technique for definition of inputs and costs associated with analgesia and treatment of adverse side effects. The estimation of direct medical costs included: costs of medication used for control of postoperative pain and costs of treatment of adverse side effects. Other costs (costs of surgical procedure, preoperative period and other postoperative procedures) were considered similar and independent of the medication used for postoperative analgesia.

Information on resources required for medical procedures of postoperative analgesia were estimated using the Brazilian Hierarchical Classification of Medical Procedures (Classificação Brasileira Hierarquizada de Procedimentos Médicos).${ }^{11}$ Information on inputs necessary for treatment of adverse side effects of postoperative analgesia (nausea and vomit) was not available in the Brazilian Unified Health System; thus, the microcosting technique was applied based on guidelines for treatment from Hospital Israelita Albert Einstein, ${ }^{12}$ one of the main private hospitals in the city of São Paulo.
Information on the cumulative utilization of anesthetic reported in the literature was used to determine the dosage of fentanyl and sufentanil during two days of treatment. ${ }^{8}$

The inputs required for treatment of adverse side effects in the first day were: two clinical assessments, adoption of enteral nutrition, and administration of ondansetron, omeprazole, metoclopramide and bromopride. The inputs required for treatment of adverse side effects in the second day were: two clinical assessments, and administration of ondansetron, omeprazole, metoclopramide and bromopride. ${ }^{12}$

Prices of medication used for control of postoperative pain and treatment of adverse side effects were used to estimate costs, regarding government purchases (named Maximum Price for Sale to Government, PMVG ${ }^{13}$ with additional $18 \%$ of Tax on Circulation of Goods and Services (ICMS).

Prices of other inputs used for and treatment of adverse side effects were based on the Brazilian Hierarchical Classification of Medical Procedures ${ }^{11}$ and reference prices for medical treatments in the Brazilian Unified Health System.

Prices of inputs for postoperative analgesia and treatment of adverse side effects were collected in Brazilian currency (reais) in August 2014, updated to September 2015 using the National Consumers' Prices Index of the Brazilian Institute for Geography and Statistics (IPCAIBGE), and converted to U.S. dollars using official exchange rates published by the Brazilian Central Bank.

The global costs of postoperative pain control strategies for treatment of adult patients with cancer using fentanyl and sufentanil were estimated based on the following equation:

$$
c_{i}=\sum_{q i} \times p i
$$

Where: $\mathrm{c}_{\mathrm{i}}=$ global cost of postoperative pain control strategy $i ; \mathrm{q}_{\mathrm{i}}=$ quantity of anesthetic $i ; \mathrm{p}_{\mathrm{i}}=$ price of anesthetic $i$ for government acquisition; $\mathrm{P}\left(\mathrm{ae}_{\mathrm{i} 1}\right)=$ probability of adverse effects using the anesthetic $i$ in the first postoperative day; $\mathrm{q}_{1 \mathrm{~m}}=$ quantity of $m$ inputs necessary for treatment of adverse effects in the first postoperative day; $\mathrm{p}_{1 \mathrm{~m}}=$ price of $m$ inputs necessary for treatment of adverse effects in the first postoperative day; $\mathrm{P}\left(\mathrm{ae}_{\mathrm{i} 2}\right)=$ probability of adverse effects using the anesthetic $i$ in the second postoperative day; $\mathrm{q}_{2 \mathrm{n}}=$ quantity of $n$ inputs necessary for treatment of adverse effects in the first second postoperative day; $\mathrm{p}_{2 \mathrm{n}}=$ price of $n$ inputs necessary for treatment of adverse effects in the second postoperative day. 
The probabilities of occurrence of each outcome were inserted in the software TreeAge Pro 2014, including the costs estimated for each treatment strategy (fentanyl and sufentanil). Each branch of the decision tree included the calculation of cumulative probabilities of outcomes and costs, in order to allow the comparison of global outcomes expected for each treatment strategy and respective costs.

\section{Sensitivity analysis}

A univariate sensitivity analysis was conducted in order to verify robustness of the model and to identify the variables that may influence significantly the results obtained in the base case.

An incremental cost-effectiveness ratio (ICER) was estimated using the base case parameters of the economic assessment model and recalculated considering variations in each parameter inserted in the base case scenario, in order to estimate the potential impacts on the decision processes within the Brazilian Unified Health System regarding changes in postoperative pain control strategies for adult patients with cancer.

Patterns of variability in parameters relating to outcomes and medication dosage were based on information of standard deviation obtained from literature review. ${ }^{8}$ Other parameters were submitted to a variation of $\pm 20 \%$ in relation to the initial value established, a range of variability considered appropriate to analyze potential changes in the health system scenario that may influence the ICER.

The univariate sensitivity analysis was conducted using the software TreeAge Pro 2014, by estimating the changes occurring in the ICER due to modification of key parameters in outcomes and costs to verify robustness of the model.

\section{ResULTS}

\section{Literature review}

There were 212 records identified in the Medline/PubMed and Lilacs databases, 21 records were duplicated. Considering the 191 remaining records screened, 178 were excluded due to identification of:

- $\quad$ Studies based on animals models $=3$.

- Studies based on other treatments $=74$.

- Studies based on alternative administration ways $($ nasal or transdermal $)=5$.

- $\quad$ Studies without outcomes of interest $=53$.

- $\quad$ Case studies $=43$.

The records selected on the screening (13) were searched for full-text access and analysis; however, five records were found to have full-text unavailable. The fulltext of the eight remaining references were obtained and analyzed, in order to evaluate the information available; and four full-texts were excluded due to lack of quantitative measurement of outcomes. Therefore, four full-texts were considered as source of data for decision tree modeling and economic assessment regarding the control of postoperative pain related to cancer surgical treatment.-10

Three studies analyzed intravenous administration of postoperative analgesia, controlled by the patient, , $^{8-10}$ and the fourth study indicated use of epidural analgesia ${ }^{7}$. Only one study presented analgesia on demand, ${ }^{9}$ and the other three presented continuous infusion with bolus, if necessary. ${ }^{7,8,10}$ Two studies analyzed intensity of pain during the 48 hour period after surgery,, 8 one study analyzed it during a period of 24 hours after surgery ${ }^{9}$ and one study analyzed it during a period of 96 hours after surgery. ${ }^{10}$ Each study analyzed different comparators and different combinations of medication for analgesia. Only one study directly compared fentanyl and sufentanil without associating other medication in the analgesia. ${ }^{8}$

Considering the possibilities of variation in the postoperative analgesia, using different ways of administration, infusion cycles and blocking periods, as well as several associations of medication in the clinical practice and diverse study designs and samples in the studies identified in the literature, the analysis of economic assessment was based on the direct comparison presented between fentanyl and sufentanil without associating any other medication in the analgesia, ${ }^{8}$ using information on effectiveness and safety of the medication presented in the study.

\section{Economic assessment}

Parameters used to build the decision tree for economic assessment of postoperative pain control strategies using fentanyl and sufentanil for adult patients with cancer within the Brazilian Unified Health System were based on probability of adverse side effects, VAS points for characterization of postoperative pain, medical procedures necessary to perform postoperative analgesia and treatment of adverse side effects of fentanyl and sufentanil use (Table 1).

The economic assessment included two possible health status, occurrence or absence of nausea and vomit, as represented in the decision tree (Figure 1). Values presented for each path of the decision tree represent the probabilities of each health status, and the expected outcomes with respective expected costs are presented at the end of the path. 
The use of sufentanil for postoperative analgesia was dominant in relation to the use of fentanyl, based on costeffectiveness ratios estimated with the parameters defined in the decision tree model; it should be considered that sufentanil presented lower cost (US\$25.72) and better outcome (1.6 VAS points of pain) in comparison to the cost (US\$32.58) and outcome (2.6 VAS points of pain) obtained with treatment using fentanyl.

\section{Sensitivity analysis}

Parameters that presented the highest impact on ICER were the occurrence of adverse side effects (nausea and vomit) in the second day after surgery due to use of sufentanil among patients who did not have adverse side effects in the first day, VAS points of pain due to use of sufentanil and cost of treatment with sufentanil (Table 2).

The variability in VAS points of pain by postoperative analgesia using sufentanil contributed significantly to reinforce the dominance in comparison to fentanyl, in addition to the probability of adverse side effects in the second postoperative day for patients using sufentanil who did not have adverse side effects in the first postoperative day (Figure 2).

TABLE 1 Characterization of costs for economic assessment of postoperative pain control strategies for adult patients with cancer (fentanyl and sufentanil). Brazil, 2015.

\begin{tabular}{|c|c|c|c|}
\hline Characterization & Source & Unit & Value \\
\hline \multicolumn{4}{|l|}{ Treatment using fentanyl } \\
\hline Price of fentanyl (mg) & CMED $2014^{13}$ & US\$ & 0.003 \\
\hline Cost of fentanyl ( 2 day treatment) & Lin et al. $2006,{ }^{8}$ CMED $2014^{13}$ & US\$ & 5.50 \\
\hline VAS (48h) & Lin et al. $2006^{8}$ & pt. & 2.6 \\
\hline Prob. nausea/vomit $24 \mathrm{~h}$ after surgery & Lin et al. $2006^{8}$ & $\%$ & $13 \%$ \\
\hline Prob. nausea/vomit $48 \mathrm{~h}$ after surgery & Lin et al. $2006^{8}$ & $\%$ & $8 \%$ \\
\hline \multicolumn{4}{|l|}{ Treatment using sufentanil } \\
\hline Price of sufentanil ( $\mu \mathrm{g})$ & CMED $2014^{13}$ & US\$ & 0.093 \\
\hline Cost of sufentanil (2 day treatment) & Lin et al. $2006,{ }^{8}$ CMED $2014^{13}$ & US\$ & 14.74 \\
\hline VAS $(48 h)$ & Lin et al. $2006^{8}$ & pt. & 1.6 \\
\hline Prob. nausea/vomit $24 \mathrm{~h}$ after surgery & Lin et al. $2006^{8}$ & $\%$ & $7 \%$ \\
\hline Prob. nausea/vomit $48 \mathrm{~h}$ after surgery & Lin et al. $2006^{8}$ & $\%$ & $0 \%$ \\
\hline Cost of $1^{\text {st }}$ day with nausea/vomit & CBHPM 2014, ${ }^{11}$ CMED $2014^{13}$ & US\$ & 96.19 \\
\hline Cost of $2^{\text {nd }}$ day with nausea/vomit & CBHPM 2014, ${ }^{11}$ CMED $2014^{13}$ & US\$ & 60.63 \\
\hline
\end{tabular}

TABLE 2 Characterization of costs for economic assessment of postoperative pain control strategies for adult patients with cancer (fentanyl and sufentanil). Brazil, 2015.

\begin{tabular}{|c|c|c|c|}
\hline Parameter & Variation & ICER $_{\min }$ & ICER $_{\max }$ \\
\hline Prob. AE $2^{\text {nd }}$ day - Patients without AE $1^{\text {st }}$ day (sufentanil) & $0.0-0.2$ & -0.87 & 10.57 \\
\hline VAS points of pain (sufentanil) & $7.5-9.3$ & -8.68 & -0.46 \\
\hline Cost of treatment (sufentanil) & $0.0745-0.1117$ & -3.81 & 2.07 \\
\hline VAS points of pain (fentanyl) & $5.9-8.9$ & -3.47 & 1.74 \\
\hline Prob. AE $1^{\text {st }}$ day (fentanyl) & $0.104-0.156$ & -3.27 & 1.53 \\
\hline Dosage of sufentanil (total) & 135.7-180.9 & -2.97 & 1.23 \\
\hline Cost $1^{\text {st }}$ day treatment of $\mathrm{AE}$ & $76.95-115.43$ & -2.46 & 0.73 \\
\hline Prob. AE $1^{\text {st }}$ day (sufentanil) & $0.056-0.084$ & -2.23 & 0.49 \\
\hline Cost of treatment (fentanyl) & $0.0025-0.039$ & -1.79 & 0.51 \\
\hline Prob. AE $2^{\text {nd }}$ day - Patients with AE $1^{\text {st }}$ day (sufentanil) & $0.8-1.0$ & -1.37 & -0.87 \\
\hline Cost $2^{\text {nd }}$ day treatment of $\mathrm{AE}$ & $48.51-72.76$ & -1.30 & -0.44 \\
\hline Prob. AE $2^{\text {nd }}$ day - Patients without AE $1^{\text {st }}$ day (fentanyl) & 0.064-0.096 & -1.72 & -0.01 \\
\hline Dosage of fentanyl (total) & $1,402.0-1,858.0$ & -1.64 & -0.10 \\
\hline Prob. AE $2^{\text {nd }}$ day - Patients with AE $1^{\text {st }}$ day (fentanyl) & $0.8-1.0$ & -0.87 & 0.06 \\
\hline
\end{tabular}

AE: adverse side effects of analgesia. 


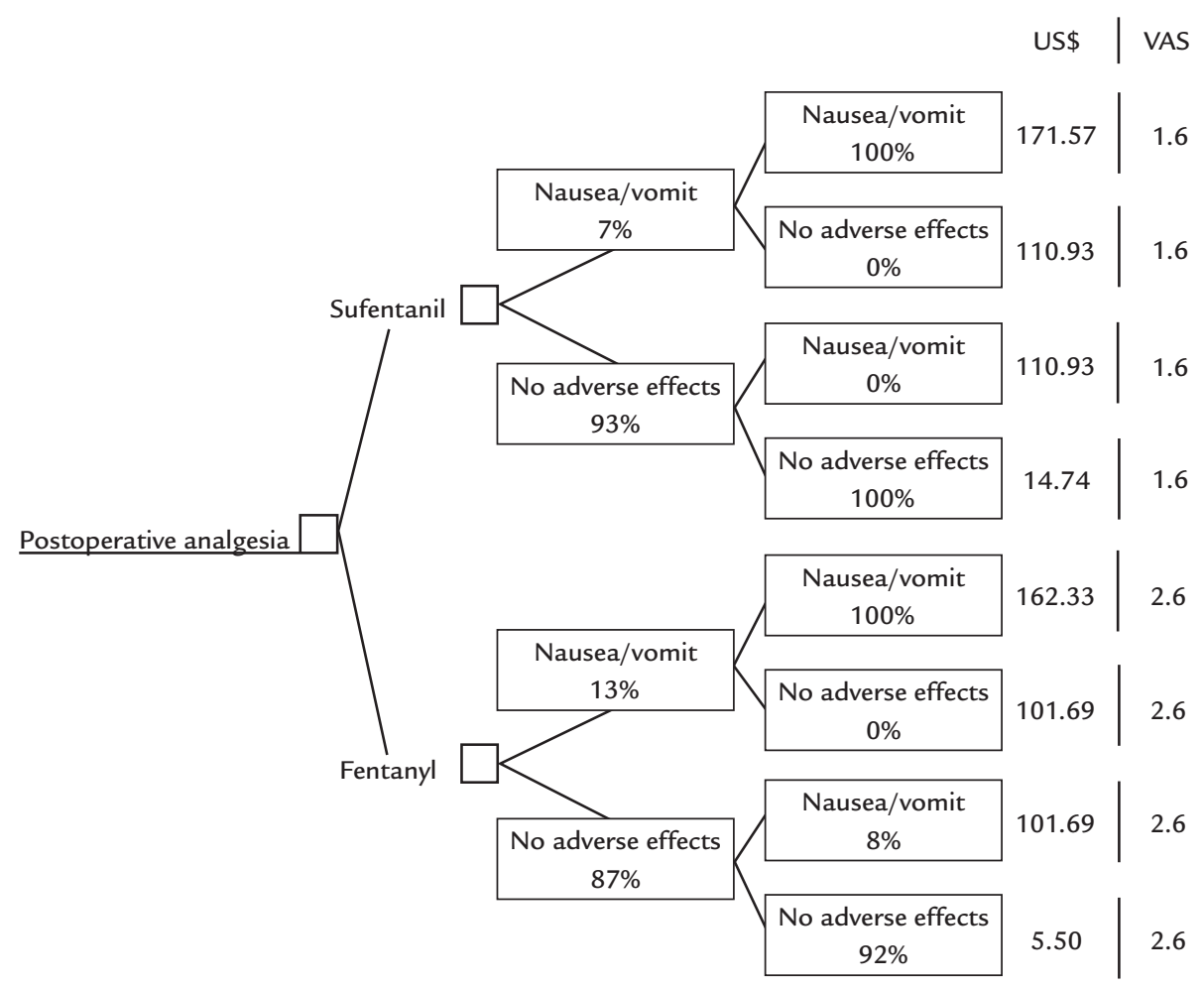

\begin{tabular}{|c|c|c|c|c|}
\hline \multicolumn{2}{|c|}{ Postoperative pain control strategy using sufentanil during two days } & \multirow[t]{2}{*}{ Cumulative probability } & \multirow[t]{2}{*}{ Cost (US\$) } & \multirow[t]{2}{*}{ Total (US\$) } \\
\hline Occurrence of adverse effects & Description of treatment & & & \\
\hline \multirow[t]{3}{*}{ During 2 days } & Administration of sufentanil & \multirow[t]{3}{*}{$7.00 \%$} & 14.74 & \multirow[t]{3}{*}{171.57} \\
\hline & Adverse effects treatment ( $1^{\text {st }}$ day) & & 96.19 & \\
\hline & Adverse effects treatment ( $2^{\text {nd }}$ day $)$ & & 60.63 & \\
\hline \multirow[t]{2}{*}{ During $1^{\text {st }}$ day } & Administration of sufentanil & \multirow[t]{2}{*}{$0.00 \%$} & 14.74 & \multirow[t]{2}{*}{110.93} \\
\hline & Adverse effects treatment ( $1^{\text {st }}$ day) & & 96.19 & \\
\hline \multirow[t]{2}{*}{ During $2^{\text {nd }}$ day } & Administration of sufentanil & \multirow[t]{2}{*}{$0.00 \%$} & 14.74 & \multirow[t]{2}{*}{110.93} \\
\hline & Adverse effects treatment ( $1^{\text {st }}$ day) & & 96.19 & \\
\hline No adverse effects & Administration of sufentanil & $93.00 \%$ & 14.74 & 14.74 \\
\hline
\end{tabular}

\begin{tabular}{|c|c|c|c|c|}
\hline \multicolumn{2}{|c|}{ Postoperative pain control strategy using fentanyl during two days } & \multirow[t]{2}{*}{ Cumulative probability } & \multirow[t]{2}{*}{ Cost (US\$) } & \multirow[t]{2}{*}{ Total (US\$) } \\
\hline Occurrence of adverse effects & Description of treatment & & & \\
\hline \multirow[t]{3}{*}{ During 2 days } & Administration of fentanyl & \multirow[t]{3}{*}{$13.00 \%$} & 5.50 & \multirow[t]{3}{*}{162.33} \\
\hline & Adverse effects treatment ( $1^{\text {st }}$ day) & & 96.19 & \\
\hline & Adverse effects treatment ( $2^{\text {nd }}$ day) & & 60.63 & \\
\hline \multirow[t]{2}{*}{ During $1^{\text {st }}$ day } & Administration of fentanyl & \multirow[t]{2}{*}{$0.00 \%$} & 5.50 & \multirow[t]{2}{*}{101.69} \\
\hline & Adverse effects treatment ( $1^{\text {st }}$ day) & & 96.19 & \\
\hline \multirow[t]{2}{*}{ During $2^{\text {nd }}$ day } & Administration of fentanyl & \multirow[t]{2}{*}{$6.96 \%$} & 5.50 & \multirow[t]{2}{*}{101.69} \\
\hline & Adverse effects treatment ( $1^{\text {st }}$ day) & & 96.19 & \\
\hline No adverse effects & Administration of fentanyl & $80.04 \%$ & 5.50 & 5.50 \\
\hline
\end{tabular}

FIGURE 1 Decision tree for economic assessment of postoperative pain control strategies for adult patients with cancer (fentanyl and sufentanil). Brazil, 2015. 


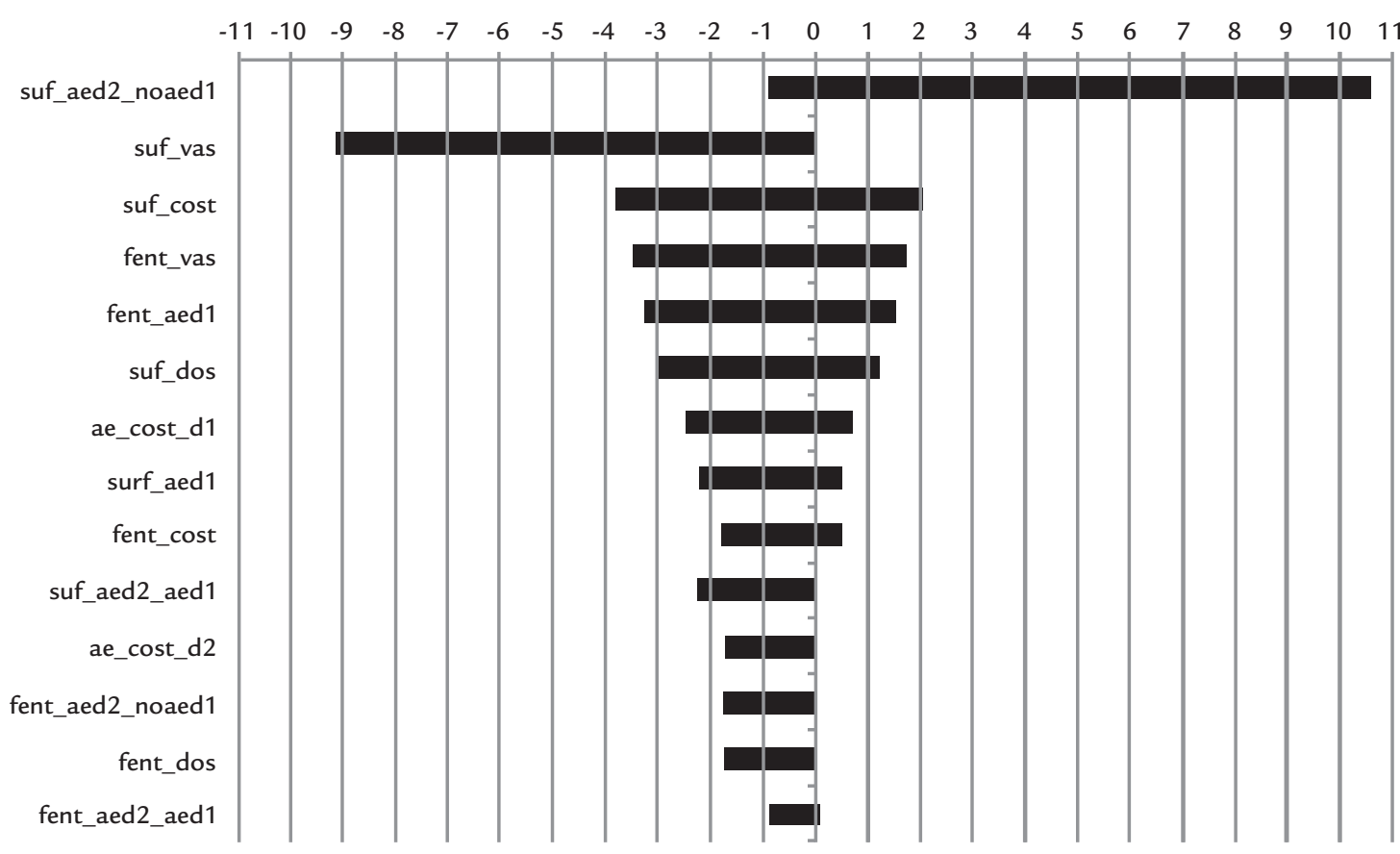

FIGURE 2 Tornado diagram based on sensitivity analysis of economic assessment of postoperative pain control strategies (fentanyl and sufentanil). Brazil, 2015.

Obs.: ae_cost_d1: cost $1^{\text {st }}$ day treatment $A E$; ae_cost_d2: cost $2^{\text {nd }}$ day treatment AE; fent_aed1: probability AE $1^{\text {st }}$ day using fentanyl; fent_aed 2_aed1: probability AE $2^{\text {nd }}$ day for patients using fentanyl with AE $1^{\text {st }}$ day; fent_aed2_noaed1: probability AE $2^{\text {nd }}$ day for patients using fentanyl without AE $1^{\text {st }}$ day; fent_cost: cost of treatment using fentanyl; fent_dos: dosage of fentanyl; fent_vas: VAS points of pain using fentanyl; suf_aed1: probability AE $1^{\text {st }}$ day using sufentanil; suf_aed2_aed1: probability AE $2^{\text {nd }}$ day for patients using sufentanil with AE $1^{\text {st }}$ day; suf_aed2_noaed1: probability $A E 2^{\text {nd }}$ day for patients using sufentanil without $A E 1^{\text {st }}$ day; suf_cost: cost of treatment using sufentanil; suf_dos: dosage of sufentanil; suf_vas: VAS points of pain using sufentanil. AE: adverse side effects of analgesia.

\section{Discussion}

There were no studies assessing cost-effectiveness of adopting fentanyl and sufentanil for postoperative analgesia in the literature review that could allow a comparison with the results obtained in the present study. Furthermore, the literature review conducted in this study showed a lack of other studies regarding effectiveness and safety of treatment using fentanyl and sufentanil for postoperative analgesia on oncologic surgeries, especially economic assessments involving cancer treatment in Brazil.

The structured question used for literature review to search scientific evidences returned only four international studies, and only one of them presented a direct comparison between fentanyl and sufentanil. Considering the wide array of techniques for postoperative analgesia, significant part of the studies was not suitable for comparison of postoperative pain control strategies using fentanyl and sufentanil. Thus, there were a limited number of appropriate parameters to build the decision tree model and proceed to economic assessment of postoperative analgesia. ${ }^{8}$

However, two studies analyzed ${ }^{7,9}$ in the literature review showed higher effectiveness of fentanyl and sufentanil in relation to any other medication used as a comparator; except the fourth study ${ }^{10}$ which presented better outcomes of postoperative analgesia based on ropivacaine in relation to fentanyl. However, it is important to point out that the aim of the study was to test the efficacy of ON-Q pain management system; ${ }^{10}$ that is, the focus was on the technique for administering postoperative anesthetics.

Both fentanyl and sufentanil presented VAS lower than four, considered the limit for satisfactory analgesia. ${ }^{7}$ The costs of treatment with fentanyl was higher than the costs of treatment with sufentanil especially due to the incidence of adverse side effects (nausea and vomit) among patients using fentanyl and due to the higher costs for the treatment of adverse side effects in comparison to the anesthetics prices.

The ICER of sufentanil in comparison to fentanyl may be considered marginal (approximately US $\$ 6.87$ per VAS point of pain), however, there are evidences that the substitution of fentanyl for sufentanil would represent an annual cost reduction of approximately US\$20,000 to the Brazilian Unified Health System, considering only the number of cancer surgeries in the state of São Paulo. ${ }^{14}$ 
Sensitivity analysis performed in the study showed that the estimated economic assessment model presented low variation in ICER due to changes in most parameters of the model, indicating robustness to scenario fluctuations. However, it is important to notice that there was high sensitivity to variation in the probability of adverse side effects in the second day among patients who did not have adverse side effects in the first day using sufentanil (variation of up to US\$ 10.57 per additional VAS point of pain reduced).

A study conducted with 808 patients in the United States investigated the limits of patients' willingness to pay for reduction of postoperative pain, indicating that patients in pain would be willing to pay up to US\$ 35 for perfect analgesia. ${ }^{15}$ The study suggests that the use of sufentanil should be considered cost-effective in relation to fentanyl even considering the worst case scenario presented on the sensitivity analysis.

The second parameter influencing ICER was the VAS points of pain in the utilization of sufentanil, reinforcing the dominance of sufentanil in comparison to fentanyl. It is important to notice that the sensitivity analysis showed less ICER variability in relation to the other parameters analyzed, resulting in variations from-US\$ 3.81 to up to US\$2.07 per VAS point of pain reduced.

The main limitations of the study presented include: utilization of data from literature review based on population from other countries due to absence of studies performed in Brazil; significant sensitivity of the model in relation to one key parameter; and lack of observational studies with representativeness at population level, especially involving the Brazilian population, in order to provide additional information on effectiveness and safety of postoperative analgesia relating to cancer treatment.

\section{Conclusion}

The economic assessment developed based on the decision tree model for postoperative pain control strategies for adult patients with cancer showed dominance of sufentanil in comparison to fentanyl, due to lower costs of treatment and better outcomes in health status. The sensitivity analysis performed showed robustness of the model, based on parameters derived from literature review and data collection on medical procedures and costs.

The results obtained suggest the need for Brazilian studies on the cost-effectiveness of adoption of fentanyl and sufentanil for postoperative analgesia, in order to validate the premises adopted in the present study and allow for the use of real life data to improve robustness and reliability of economic assessment models designed for comparison of postoperative pain control strategies using fentanyl and sufentanil.

\section{Resumo}

Avaliação econômica de estratégias para controle da dor pós-operatória para tratamento de pacientes adultos com câncer

Objetivo: $\mathrm{O}$ artigo apresenta uma avaliação econômica de opioides atualmente utilizados no controle de dor pós-operatória relacionada ao tratamento cirúrgico do câncer (fentanil e sufentanil) no contexto do Sistema Único de Saúde. Método: A avaliação baseou-se na perspectiva do governo, de forma a colaborar na promoção da efetividade das políticas públicas de saúde e melhorar a alocação de recursos públicos em saúde. Uma análise custo-efetividade foi realizada a partir de dados coletados no Sistema Único de Saúde e de informações provenientes de revisão da literatura para construção de uma árvore de decisão contendo alternativas para controle de dor pós-operatória relacionada ao tratamento cirúrgico do câncer entre pacientes adultos. Os desfechos considerados foram: efetividade da analgesia pós-operatória e ocorrência de náusea e vômito no período de 48 horas após cirurgia e em ciclos adicionais de 24 horas de seguimento do paciente. Uma análise de sensibilidade univariada foi conduzida para verificar a robustez do modelo estimado.

Resultados: Na revisão de literatura, um número limitado de estudos efetuou comparação direta entre fentanil e sufentanil no controle de dor pós-operatória. A adoção de sufentanil (custo $=$ U\$ 25,72 $/$ desfecho $=1,6$ pontos VAS) foi dominante em relação ao uso do fentanil (custo $=\mathrm{U} \$ 32,58 /$ desfecho $=2,6$ pontos VAS). O modelo estimado demonstrou robustez em relação a mudanças nos parâmetros analisados.

Conclusão: O sufentanil apresentou razão custo-efetividade superior em relação ao fentanil no controle de dor pós-operatória em cirurgias relacionadas ao tratamento de câncer entre pacientes adultos no Sistema Único de Saúde.

Palavras-chave: avaliação em saúde, analgesia, medição da dor.

\section{REFEREnCES}

1. Tilleul P, Weickmans H, Sean PT, Lienhart A, Beaussier M. Cost analysis applied to postoperative analgesia regimens: a comparison between parecoxib and propacetamol. Pharm World Sci. 2007; 29(4):374-9.

2. Athanasakis K, Petrakis I, Vitsou E, Pimenidou A, Kyriopoulos J. A costeffectiveness analysis of parecoxib in the management of postoperative pain in the Greek health care setting. Clin Ther. 2013; 35(8):1118-24. 
3. Ummenhofer WC, Arends RH, Shen DD, Bernards CM. Comparative spinal distribution and clearance kinetics of intrathecally administered morphine, fentanyl, alfentanil, and sufentanil. Anesthesiology. 2000; 92(3):739-53.

4. Epple J, Kubitz J, Schmidt H, Motsch J, Böttiger BW, Martin E, et al. Comparative analysis of costs of total intravenous anaesthesia with propofol and remifentanil vs. balanced anesthesia with isoflurane and fentanyl. Eur J Anesthesiol. 2001; 18(1):20-8.

5. Ministério da Saúde. Diretrizes metodológicas: diretriz de avaliação econômica. 2. ed. Brasília: Ministério da Saúde; 2014 [cited 2016 Jan 20]. Available from: http://bvsms.saude.gov.br/bvs/publicacoes/diretrizes_ metodologicas_diretriz_avaliacao_economica.pdf.

6. Nita ME, Nobre MRC, Costa AMN. Busca da evidência a partir do cenário clínico. In: Nita ME, Campino ACC, Secoli SR, Sarti FM, Nobre MRC, Costa AMN, et al., editors. Avaliação de tecnologias em saúde: evidência clínica, análise econômica e análise de decisão. Porto Alegre: Artmed; 2010.

7. Hong JY, Yang SC, Yi J, Kil HK. Epidural ropivacaine and sufentanil and the perioperative stress response after a radical retropubic prostatectomy. Acta Anaesthesiol Scand. 2011; 55(3):282-9.

8. Lin CS, Lu G, Ruan LY, Gu MN. [Patient-controlled intravenous analgesia with sufentanil and fentanyl after thoracotomy: a comparative study]. Nan Fang Yi Ke Da Xue Xue Bao. 2006; 26(2):240-1, 244.

9. Kim HS, Czuczman GJ, Nicholson WK, Pham LD, Richman JM. Pain levels within 24 hours after UFE: a comparison of morphine and fentanyl patientcontrolled analgesia. Cardiovasc Intervent Radiol. 2008; 31(6):1100-7.
10. Chung D, Lee YJ, Jo MH, Park HJ, Lim GW, Cho H, et al. The ON-Q pain management system in elective gynecology oncologic surgery: Management of postoperative surgical site pain compared to intravenous patient-controlled analgesia. Obstet Gynecol Sci. 2013; 56(2):93-101.

11. Associação Médica Brasileira. Classificação brasileira hierarquizada de procedimentos médicos. São Paulo: Associação Médica Brasileira; 2014

12. Cendoroglo Neto M, Hamerschlak N, Ribeiro AAF, Guendelmann RAK, Santos VA. Guia de protocolos e medicamentos para tratamento em oncologia e hematologia. São Paulo: Hospital Israelita Albert Einstein; 2013 [cited 2014 Aug 25]. p. 501-6. Available from: http://medicalsuite.einstein. br/pratica-medica/guias-e-protocolos/Documents/Guia_Oncologia_Einstein_2013.pdf.

13. Câmara de Regulação de Mercado de Medicamentos (CMED). Preços máximos de medicamentos por princípio ativo, para compras públicas preço fábrica (PF) e preço máximo de venda ao governo (PMVG) [cited 2014 Aug 25]. Available from: www.anvisa.org.br.

14. Gomes Junior SCS, Almeida RT. Modelo de simulação para estimar a infraestrutura necessária à assistência oncológica no sistema público de saúde. Rev Panam Salud Publica. 2009; 25(2):113-9.

15. van den Bosch JE, Bonsel GJ, Moons KG, Kalkman CJ. Effect of postoperative experiences on willingness to pay to avoid postoperative pain, nausea, and vomiting. Anesthesiology. 2006; 104(5):1033-9. 